\title{
Bazı Kişniş (Coriandrum sativum L.) Genotiplerinin Isparta Koşullarında Verim ve Kalite Özelliklerinin Belirlenmesi
}

\author{
Göksel Ali GÖKDUMAN1, İsa TELCi'² \\ ${ }^{1}$ Süleyman Demirel Üniversitesi, Fen Bilimleri Enstitüsü, 32260, Isparta \\ 2Isparta Uygulamalı Bilimler Üniversitesi, Tarım Bilimleri ve Teknolojileri Fakültesi, Tarla Bitkileri Bölümü, \\ 32260, Isparta
}

(Alınıș / Received: 01.01.2018, Kabul / Accepted: 28.09.2018, Online Yayınlanma / Published Online: 12.10.2018)

Anahtar Kelimeler
Kișniş,
Coriandrum sativum,
Verim,
Kalite,
Adaptasyon

Anahtar Kelimeler

Kişniş,

Verim,

Adaptasyon

\begin{abstract}
Özet: Bu çalışmada; ıslah edilmiş kişniş çeşit ve hatlarının Isparta ekolojik koşularına uyumu ile verim ve kalite özelikleri araştırılmıştır. Çalışma 2017 vejetasyon döneminde Süleyman Demirel Üniversitesi, Tarımsal Araştırma ve Uygulama Merkezi arazilerinde yürütülmüştür. Çalışmada Arslan, Erbaa, Pelmus, Kudret K. Gamze, Gürbüz tescilli çeşitler ile saflaştırılmış Tokat K, Tokat B ve Mardin hatları kullanılmıştır. Tarla denemesi tesadüf blokları deneme desenine göre üç tekrarlamalı olarak yürütülmüştür. Çalışma sonucunda en yüksek biyolojik verim $(450 \mathrm{~kg} / \mathrm{da})$ ve meyve verimi $(113 \mathrm{~kg} / \mathrm{da})$ Erbaa çeşidinden elde edilmiştir. Uçucu yağ ve sabit yağ oranları sırasıyla \% 0.17-0.33 ile \%18.64-22.16 aralıklarında bulunmuştur. Çalışma sonucunda, kozmetik sektörünün önemli olduğu Isparta koşullarında kişniş bitkisinden maksimum $113 \mathrm{~kg} / \mathrm{da}$ meyve verimi alınabileceği ve bölgenin kişniş üretimi için uygun olduğu belirlenmiştir. Çalışmada ayrıca Erbaa çeşidinin diğer çeşitlerden daha yüksek verim verdiği belirlenmiștir.
\end{abstract}

\section{Determination of Yield and Quality Characteristics of Some Coriander (Coriandrum sativum L.) Genotypes in Isparta Conditions}

Keywords
Coriander,
Coriandrum sativum,
Yield,
Quality,
Adaptation

\begin{abstract}
In this study, adaptation, yield and quality characteristics of coriander varieties and lines were researched in Isparta ecological conditions. The study was carried out at Suleyman Demirel University, Field of Agricultural Research and Application Center in 2017 vegetation period with 6 cultivars (Arslan, Erbaa, Pelmus, Kudret K. Gamze, Gurbuz) and 3 line (Tokat K, Tokat B and Mardin). The field experiment was carried out with 3 replications according to random block design. The highest biological yield (4500 kg/ha) and fruit yield (1130 kg/ha) were obtained from the Erbaa variety. The ratio of essential oil and seed oil is found in the range of 0.17$0.33 \%$ and $18.64-22.16 \%$, respectively. As a result of the study, it was determined that maximum fruit yield in coriander was $1130 \mathrm{~kg} / \mathrm{ha}$ in the Isparta having cosmetic sector, and production of coriander is suitable in the ecology of Isparta. Erbaa variety gave highest yield in the ecology.
\end{abstract}

\section{Giriş}

Günümüzde tıbbi ve aromatik bitkilere olan ilgi günden güne artmaktadır. Türkiye iklim ve tarımsal avantajları nedeniyle bu bitkilerin üretiminin de önemli potansiyele sahiptir. Başta orman köylüleri olmak üzere kırsal alandaki üreticiler için doğal kaynakların değerlendirilmesi ve tıbbi bitkiler tarımı bölge çiftçisinin gelirini arttırması bakımından önemlidir. Tıbbi bitkilerin kültüre alınması doğadan toplama baskısını azaltacak bunun sonucu doğal kaynakların korunmasına neden olacaktır.
Apiaceae familyasına ait Kişniş (Coriandrum sativum L.) taze yapraklar; sebze yemeklerinde, çorbalarda, salatalarda ve soslarda kullanılmaktadır. Kişnişin meyvelerinden uçucu yağ üretimi yapılarak kozmetik, ilaç ve baharat sanayiinde kullanılmaktadır.

Kişniş antik çağlardan günümüze kadar bilinen bir bitkidir. $\mathrm{Bu}$ bitki 3000 yıldan beri Mısır, Çin ve Hindistan'da baharat ve tıbbi amaçla kullanılmaktadır [1]. Günümüzde kişniş taze ve kuru yaprakları baharat ve sebze olarak kullanılması yanında olgun meyveleri (Fructus Coriandri T.K.) ögütülerek direk baharat olarak kullanılmaktadır. 
Kişnişte lokal olarak kullanılan taze herbası yanında, ana ürün olgun meyveleridir. Meyvelerde uçucu yă̆ ve linalool oranının yüksek olması nedeniyle kozmetikte önemlidir. Ayrıca öğütülmüş olgun meyveler baharat olarak kullanılmaktadır [2,3].

Meyvelerin uçucu yağ oranı \% $0.03-2.60$ arasında linalool oranları ise \% 50-70 arasında değişmektedir $[2,3,4,5] \mathrm{Bu}$ nedenlerden dolayı Türkiye'de özellikle ilaç ve baharat bitkileri üretimi bakımından önemli bir potansiyele sahiptir. Isparta da kuru tarım koşullarında ıslah edilmiş kişniş çeşitleri ile ilgili çalışmaların sınırlı olması nedeniyle; mevcut çalışmada; ıslah edilmiş 6 kişniş çeşidi ile yeni geliștirilmiş iki hattın bölgedeki adaptasyon ve verim potansiyellerinin belirlenmesi amaçlanmıştır.

\section{Materyal ve Metot}

Denemenin yürütüldüğü Isparta ili, $1050 \mathrm{~m}$ rakımlı Akdeniz ile Orta Anadolu bölgesinin geçiş alanında yer almaktadır. Tipik bir karasal iklimin hüküm sürdüğü bölgede, iklim kışları soğuk ve yağışlı, yazları sıcak ve kurak geçmektedir. Çalışma 2017 yılı vejetasyon döneminde kurulmuştur. Deneme yılı ve uzun yıllara ait iklim verileri Tablo 1'de verilmiştir.

Tablo 1. Deneme yılına ve uzun yıllara ait iklim verileri [6]

\begin{tabular}{lcccc}
\hline & \multicolumn{2}{c}{$\begin{array}{c}\text { Ortalama sıcaklık } \\
\left({ }^{\circ} \mathrm{C}\right)\end{array}$} & \multicolumn{2}{c}{$\begin{array}{c}\text { Toplam Yağış } \\
(\mathrm{mm})\end{array}$} \\
\cline { 2 - 5 } Aylar & 2017 & Uzun yıllar & 2017 & Uzun yıllar \\
\hline Mart & 7.3 & 6.2 & 74.4 & 55.0 \\
Nisan & 10.6 & 10.8 & 25.6 & 55.3 \\
Mayıs & 14.9 & 15.6 & 149.5 & 30.6 \\
Haziran & 20.1 & 20.2 & 30.9 & 14.6 \\
Temmuz & 25.0 & 23.7 & 13.1 & 11.7 \\
Ort./Top. & 15.5 & 15.3 & 293.5 & 167.2 \\
\hline
\end{tabular}

Deneme alanı düz ve düze yakın topoğrafik yapıda yer almaktadır. Deneme alanı toprağı kumlu-tınlı bir yapıya sahip olup, bazik, kireç oranı yüksek ve organik madde oranı düşük yapıdadır.

Çalışma 2017 vejetasyon döneminde Süleyman Demirel Üniversitesi, Tarımsal Araștırma ve Uygulama Merkezi arazilerinde yürütülmüştür. Çalışmada Arslan, Erbaa, Pelmus, Kudret K. Gamze, Gürbüz tescilli çeşitler ile Tokat K, Tokat B ve Mardin popülasyonlarından saflaştırılmış hatlar kullanılmıştır. Tarla deneme 23.03.2017 tarihinde yazlık olarak kurulmuştur. Tarla denemesi tesadüf blokları deneme desenine göre 3 tekrarlamalı olarak yürütülmüștür.

Araştırmada parsel uzunlukları $3 \mathrm{~m}$, genişlikleri $1.5 \mathrm{~m}$ olup parsel alanı $4.5 \mathrm{~m}^{2}$ dir. Parsellerde sıra arası 30 cm olarak ayarlanmış ve 1.0-1.1 kg/da ekim normunda tohum atılmıştır. Denemede yabancı ot mücadelesi elle yapılmıştır. Olum döneminde bitkilerde biyolojik verim ve meyve verimi ile birlikte uçucu yağ ile sabit yağ oranları incelenmiştir.
Uçucu yağ oranı (\%) : Hafif öğütülen olgun meyvelerde distilasyon yöntemiyle Clevenger aparatı kullanılarak belirlenmiştir [7].

Sabit Yağ Oranı (\%): Her parselden alınan tohum örnekleri de Nükleer Manyetik Rezonans spektroskopisi ile belirlenmiştir.

Denemede elde edilen verilerin istatistiksel analizleri tesadüf blokları deneme desenine göre SPSS (var. 18) paket programı kullanılarak değerlendirilmiştir. Ortalamalar arasındaki farklılıklar Duncan testine göre gruplandırılmıştır.

\section{Bulgular ve Tartışma}

Kişniş genotipleri arasında biyolojik verimler yönünden önemli $(\mathrm{p}<0.01)$ farklılıklar saptanmıştır.

Tablo 2. Kişniş çeşit ve hatlarının biyolojik verimine ait ortalama değerler

\begin{tabular}{llc}
\hline Sira no & Çeşit/hat & $\begin{array}{c}\text { Biyolojik } \\
\text { verim(kg/da)** }\end{array}$ \\
\hline 1 & Tokat-K & $403.2^{\mathrm{ab}}$ \\
2 & Arslan & $311.8^{\mathrm{b}}$ \\
3 & Gürbüz & $360.9^{\mathrm{ab}}$ \\
4 & Tokat-B & $324.7^{\mathrm{b}}$ \\
5 & Gamze & $311.9^{\mathrm{b}}$ \\
6 & Pelmus & $362.4^{\mathrm{ab}}$ \\
7 & Mardin & $183.7^{\mathrm{c}}$ \\
8 & Kudret K & $363.5^{\mathrm{ab}}$ \\
9 & Erbaa & $450.0^{\mathrm{a}}$ \\
\hline${ }^{* *} \mathrm{p}<0.01$ & &
\end{tabular}

Genotiplerde biyolojik verim 183.7 ile $450.0 \mathrm{~kg} / \mathrm{da}$ $\mathrm{kg} / \mathrm{da}$ arasında değişmiştir (Tablo 2). En yüksek biyolojik verim, Erbaa çeşidinden (450.0 kg/da) elde edilmiş, bunu $403.0 \mathrm{~kg} /$ da ile Tokat-K izlemiştir. Bu çeşitler istatistiksel olarak aynı grupta yer almıştır. En düşük biyolojik verim ise $183.7 \mathrm{~kg} / \mathrm{da}$ ile erkenci ve kısa boylu olan Mardin genotipinden elde edilmiştir. Biyolojik verim toprak üstü aksamın kütlesel verimiyle ilgili olup, çeşitlere ve iklime göre değişmektedir. Ekim zamanına bağlı olarak çeşitlerde biyolojik verim önemli oranda etkilenmektedir. Geciken ekimlerde vejetasyon süresinin kısalığına bağlı biyolojik verimde düşük olmaktadır. Ayrıca yapılan çalışmalarda erkenci çeşitlerde biyolojik verim de düşük bulunmuştur [7]. Bu nedenle en erkenci ve kısa boylu Mardin hattından [7] en düşük verim alınırken, yüksek boylu geççi çeşitlerde yüksek biyolojik verim elde edilmiştir [8].

Çeşit ve hatlarda meyve verimi $47.1 \mathrm{~kg} / \mathrm{da}$ ile 113.2 $\mathrm{kg} / \mathrm{da}$ arasında değişmiş ve genotipler arasındaki bu fark istatistiksel olarak önemli $(\mathrm{p}<0.05)$ olmuştur. En yüksek meyve verimi $113.2 \mathrm{~kg} / \mathrm{da}$ ile Erbaa çeşidinden elde edilmiş, bunu $103.2 \mathrm{~kg}$ ile Pelmus çeşidi takip etmiştir. En düşük meyve verimi ise 47.1 $\mathrm{kg} / \mathrm{da}$ ile erkenci Mardin genotipinden alınmıştır (Tablo 3). 
Tablo 3. Kişnis çeșit ve hatlarının dekara meyve verimine ait ortalama değerler

\begin{tabular}{llc}
\hline Sira no & Ceşit/hat & Meyve verimi $(\mathrm{kg} / \mathrm{da})^{*}$ \\
\hline 1 & Tokat-K & $86.5^{\mathrm{b}}$ \\
2 & Arslan & $84.02^{\mathrm{b}}$ \\
3 & Gürbüz & $95.3^{\mathrm{ab}}$ \\
4 & Tokat-B & $90.5^{\mathrm{ab}}$ \\
5 & Gamze & $92,6^{\mathrm{ab}}$ \\
6 & Pelmus & $103.2^{\mathrm{ab}}$ \\
7 & Mardin & $47.6^{\mathrm{c}}$ \\
8 & Kudret K & $88.1^{\mathrm{ab}}$ \\
9 & Erbaa & $113.2^{\mathrm{a}}$ \\
\hline${ }^{*} \mathrm{p}<0.05$ & &
\end{tabular}

Kişnişte esas değerlendirilen kısım meyveler olduğu için meyve verimleri önemli bir özelliktir $(7,8,9)$. Meyve verimi iklim, çeşit, genetik yapı, çevre şartları ve ekim zamanlarına göre önemli değişimler göstermektedir [9,10,11,12]. Aynı çeşitlerle Tokat koşullarında yapılan çalışmada kışlık ekimlerde işlemlere göre verimler 102.9-251.6 kg/da aralığında; yazlık ekimlerde ise 78.7-165.6 kg/da aralığında bulunmuştur [8].

Tablo 4. Kişniş çeşit ve hatlarının uçucu yağ oranına ait ortalama değerleri.

\begin{tabular}{llc}
\hline Sıra no & Çeşit/hat & Uçucu yağ oranları $(\%)^{* *}$ \\
\hline 1 & Tokat-K & $0.32^{\mathrm{a}}$ \\
2 & Arslan & $0.17^{\mathrm{c}}$ \\
3 & Gürbüz & $0.17^{\mathrm{c}}$ \\
4 & Tokat-B & $0.22^{\mathrm{b}}$ \\
5 & Gamze & $0.27^{\mathrm{bc}}$ \\
6 & Pelmus & $0.25^{\mathrm{b}}$ \\
7 & Mardin & $0.22^{\mathrm{b}}$ \\
8 & Kudret K & $0.24^{\mathrm{b}}$ \\
9 & Erbaa & $0.33^{\mathrm{a}}$ \\
\hline${ }^{* *} \mathrm{p}<0.01$ & &
\end{tabular}

Kişniş çeşit ve hatlarının uçucu yağ oranları incelendiğinde; uçucu yağ oranları 0.17-0.33 arasında değişmiştir (Tablo 4). Çalışmada en yüksek uçucu yağ oranı Erbaa çeşidi (\% 0.33) ile Tokat-K hattından (\% 0.32 ) elde edilmiştir. En düşük uçucu yağ oranları ise \% 0.17 ile Arslan ve Gürbüz çeșitlerinden elde edilmiștir. Gücük [8] aynı çeșitlerle yaptığı çalıșmada uçucu yă̆ oranı değerlerini $\% \quad 0.20$ ile $\% \quad 0.40$ arasında bulmuştur. Çalışma sonuçlarıyla uyumlu olarak en yüksek uçucu yağ oranı Erbaa çeşidinde bulunmuştur. Çalışmada elde ettiğimiz değerler yapılmış çalışmaların değişim sınırlarında yer almıştır.

En yüksek sabit yağ oranı Mardin (22.53) ve Tokat- K (22.16) hatlarından elde edilmiștir. En düşük sabit yağ oranı ise 18.64 ile Gamze çeşidinde belirlenmiştir. Yağ verimi; dekara meyve verimi ve yağ oranı ilgili olup; en yüksek meyve verimine sahip Erbaa çeşidinde en yüksek yağ verimi de elde edilmiştir (Tablo 5). Yapılan çalışmalarda kişniş tohumlarında sabit yağ yağ oranı \%9-27 arasında değiştiği ve en önemli yağ asidinin petroselinik asit olduğu bilinmektedir [13].
Tablo 5. Bazı kișniș çeșit ve hatlarının sabit yağ oranına ait ortalama değerleri.

\begin{tabular}{llc}
\hline Sıra no & Çeşit/hat & Sabit yağ oranları $(\%)^{*}$ \\
\hline 1 & Tokat-K & $22.16^{\mathrm{a}}$ \\
2 & Arslan & $18.96^{\mathrm{cd}}$ \\
3 & Gürbüz & $20.81^{\mathrm{bbc}}$ \\
4 & Tokat-B & $19.96^{\mathrm{bcd}}$ \\
5 & Gamze & $18.64^{\mathrm{d}}$ \\
6 & Pelmus & $20.31^{\mathrm{bcd}}$ \\
7 & Mardin & $22.53^{\mathrm{a}}$ \\
8 & Kudret K & $21.06^{\mathrm{ab}}$ \\
9 & Erbaa & $20.19^{\mathrm{bcd}}$ \\
\hline${ }^{*} \mathrm{p}<0.05$ & &
\end{tabular}

\section{Sonuç}

Çalışma sonucunda bölgede kişnişten çeşitlere göre değișmekle birlikte en fazla meyve verimin 113.2 $\mathrm{kg} / \mathrm{da}$ Erbaa çeşidinden elde edildiği belirlenmiştir. Aynı çeşidin uçucu yağ oranı ve veriminin de en yüksek olması, bu çeşidin bölge için önemli olabileceğini göstermektedir.

Ancak çeşit ve hatların ekolojik koşullara ve tarımsal uygulamalara göre değişimleri nedeniyle bölgede diğer uygun çeşitlerin seçimi ve yetiştirme teknikleri ile ilgili ilave çalışmalara ihtiyaç bulunmaktadır.

\section{Kaynakça}

[1] Arslan, N. ve Gürbüz, B., 1994. Değișik Bölgelerden Toplanan Kişniş (Coriandrum sativum L.) Populasyonlarında Verim ve Diğer Karakterler Üzerine Bir Araștırma I. Tarla Bitkileri Kongresi 25-29 Nisan 1994. İzmir, Bildiri Kitabı, 132-136.

[2] Diederichsen, A. 1996. Coriander: (Coriandrum sativum L) Promoting the conservation and use of underutilized and neglected crops. 3. Indernational Plant Genetic Resources Institute, Roma.

[3] Telci, I., Tonçer O.G. ., Sahbaz N., 2006. Yield, Essential Oil Content and Composition of Coriandrum sativum varieties (var. vulgare Alef and var. microcarpum DC.) Grown in Two Different Locations. Journal of Essential Oil Research 18, 2, 189-193.

[4] Telci, I., Bayram, E., Avci B. 2006. Changes in yields, essential oil and linalool contents of Coriandrum sativum varieties (var. vulgare Alef. and var. microcarpum DC.) harvested at different developed European Journal of Horticultural Science, 267-271.

[5] Telci, I, Hișil. Y. 2008. Biomass yield and herb essential oil characters at different harvest stages of spring and autumn sown Coriandrum sativum European Journal of Horticultural Science, 267-272.

[6] Anonim 2017. Meteroloji Genel Müdürlüğü Isparta Meteoroloji İstasyonun, Isparta. 
[7] Kaya, N., Yllmaz, G ve Telci, İ., 2000. Farklı Zamanlarda Ekilen Kișniș (Coriandrum sativum L.) Populasyonlarının Agronomik ve Teknolojik Özellikleri. Turk J Agric For (24):355-364.

[8] Gücük, F., 2014. Tokat Kazova Ekolojik Koşullarında Kıșlık ve Yazlık Yetiștirilen Kișniș (Coriandrum sativum L.) Çeşit ve Hatlarının Agronomik ve Kalite Özeliklerinin Belirlenmesi. Gaziosmanpaşa Üniversitesi Fen Bilimleri Enstitüsü, Tarla Bitkileri Anabilim Dalı, Yüksek Lisans Tezi, Tokat. 57 sy.

[9] Gök, N., 2011. Farklı Zamanlarda Ekilen Kişniş (Coriandrum sativum L.) Çeşitlerinin Verim ve Kalite Özelliklerinin Belirlenmesi. Yüksek Lisans Tezi, Yüzüncü Yıl Üniversitesi Fen Bilimleri Enstitüsü, Van. 57 sy.

[10] Yamanol. A., 1996. Kișniș (Coriandrum sativum L.)'in Farklı Ekim Zamanı ve Tohumluk
Miktarının Agronomik ve Teknolojik Özellikleri Üzerine Olan Etkisi. Yüksek Lisans Tezi, Ege Üniversitesi Fen Bilimleri Enstitüsü, 40s, İzmir.

[11] Tonçer Ö., Tansi L.S., 1997. Kişniş (Coriandrum sativum)de Farklı Ekim Sıklığının Verim Ve Uçucu Yağ Oranına Etkisi. C..U. Ziraat Fakültesi Dergisi, 181,155-162.

[12] Tonçer Ö., Tansı L.S., Kızıl S. 1998. The Effect of Different Sowing Time on Essential Oil of Coriander in Gap Region. Anadolu, J. of AARI 8 (2) , $101-105$.

[13] Diederichsen, A., 1996. Coriander (Coriandrum sativum L.). Promoting the conservation and use of underutilized and neglected crops. 3. Institute of Plant Genetics and Crop Plant Research, Gatersleben. International Plant Genetic Resources Institute, Rome, 55, p.83. 